\title{
Recognition of six additional cystoviruses: Pseudomonas virus phi6 is no longer the sole species of the family Cystoviridae
}

\author{
Sari Mäntynen ${ }^{1}\left[\right.$ [D $\cdot$ Lotta-Riina Sundberg ${ }^{1} \cdot$ Minna M. Poranen $^{2}$
}

Received: 6 September 2017 / Accepted: 10 December 2017 / Published online: 19 December 2017

(c) Springer-Verlag GmbH Austria, part of Springer Nature 2017

\begin{abstract}
Cystoviridae is a family of bacterial viruses (bacteriophages) with a tri-segmented dsRNA genome. It includes a single genus Cystovirus, which has presently only one recognised virus species, Pseudomonas virus phi6. However, a large number of additional dsRNA phages have been isolated from various environmental samples, indicating that such viruses are more widespread and abundant than previously recognised. Six of the additional dsRNA phage isolates (Pseudomonas phages phi8, phi12, phi13, phi2954, phiNN and phiYY) have been fully sequenced. They all infect Pseudomonas species, primarily plant pathogenic Pseudomonas syringae strains. Due to the notable genetic and structural similarities with Pseudomonas phage phi6, we propose that these viruses should be included into the Cystovirus genus (and consequently into the Cystoviridae family). Here, we present an updated taxonomy of the family Cystoviridae and give a short overview of the properties of the type member phi6 as well as the putative new members of the family.
\end{abstract}

\section{Introduction}

DsRNA viruses represent a remarkably diverse group of biological entities, infecting organisms in all three domains of life. Nine distinct dsRNA virus families (Amalgaviridae, Birnaviridae, Chrysoviridae, Cystoviridae, Endornaviridae, Partitiviridae, Picobirnaviridae, Reoviridae and Totiviridae) are currently recognised by the International Committee on Taxonomy of Viruses (ICTV). These viruses vary in terms of host specificity (ranging from bacteria to humans), number of genome segments (one to twelve) and virion organization (varying numbers of capsid layers with different triangulation (T) numbers). However, the majority of the dsRNA viruses share certain fundamental structural and functional features. These similarities reflect the challenges viruses face replicating their dsRNA genomes, while

Handling Editor: Sead Sabanadzovic.

Sari Mäntynen

sari.s.mantynen@jyu.fi

1 Centre of Excellence in Biological Interactions, Department of Biological and Environmental Science and Nanoscience Center, University of Jyväskylä, P.O. Box 35, 40014 Jyväskylä, Finland

2 Department of Biosciences, Faculty of Biological and Environmental Sciences, University of Helsinki, P.O. Box 56, 00014 Helsinki, Finland simultaneously avoiding dsRNA-triggered antiviral defense mechanisms of their host organisms [1]. DsRNA viruses overcome these challenges by delivering their genomes into the host cell within specialized icosahedral capsids, containing enzymatic activity for RNA metabolism. These multifunctional nanocompartments carry out replication and transcription as well as protect the dsRNA genome from antiviral responses [2]. Probably due to these common functional requirements, the innermost capsids are highly conserved among most of the dsRNA viruses. They consist of 120 protein subunits arranged as 60 asymmetric dimers on a $\mathrm{T}=1$ icosahedral lattice. Moreover, in most cases, the protein subunits in the capsid possess a similar fold, despite the lack of significant sequence similarity [3, 4]. This icosahedral protein shell encloses the segmented dsRNA genome and several copies of the viral RNA-dependent RNA polymerase (RdRP). Additional capsid shells, typically arranged on $\mathrm{T}=13$ icosahedral lattice, may reside on top of the inner core particle. These external layers facilitate interaction with the host, and thereby show greater diversity between dsRNA virus families [2].

Pseudomonas phage phi6, the type member of the Cystoviridae, was isolated on Pseudomonas-infested bean straw in Nebraska, USA in the beginning of 1970's [5]. It was the first - and for over two decades the only - known dsRNA virus to infect bacteria. The tripartite dsRNA genome of phi6 is enclosed in an icosahedral, double-layered protein 
capsid, which in turn is surrounded by a membrane envelope. The lipid envelope around an icosahedral protein capsid is a unique feature among bacterial viruses, though members of the Tectiviridae and Corticoviridae have lipid membranes inside their protein capsids. Due to the extensive biochemical, genetic and structural characterization, phi6 has become one of the best-known bacterial virus models and dsRNA systems. Until now, phi6 has remained the sole representative of the Cystoviridae family (and Cystovirus genus), recognised by the ICTV. However, additional dsRNA phages have been isolated $[6,7]$ and some characterized in more detail [8-15] (Table 1). These viruses share notable genetic and structural similarities with phage phi6. Consequently, we have proposed to classify them into the Cystoviridae family. Here we provide a short overview of phi6 and the proposed new members of the Cystoviridae family.

\section{Extended Cystoviridae family includes seven viruses}

Since the late 1990 's, dsRNA phages have been readily isolated from environmental samples, indicating that the members of the Cystoviridae are far more widespread and abundant than has been previously acknowledged [6-8, 13-15]. The complete nucleotide sequences of six of these phage isolates (Pseudomonas phages phi8, phi12, phi13, phi2954, phiNN and phiYY) have been determined to date [9-15]. Similarly to phi6, phages phi8, phi12, phi13 and phi2954 were isolated from bacteria-infested legumes in the USA [8, 13]. They all infect hosts belonging to genus Pseudomonas, most commonly plant pathogenic Pseudomonas syringae strains. However, this limited host range likely reflects the somewhat biased isolation method, in which the host strain of phi6, Pseudomonas syringae pv. phaseolicola HB10Y (or one of its mutants), was used in enrichment. Interestingly, a number of additional dsRNA virus isolates have been obtained by sampling from clovers and green beans at various locations in the USA [6, 7]. These virus isolates have been partially sequenced but not otherwise characterized. Nevertheless, the high frequency of dsRNA phages in these environmental samples suggests that this virus type is a common bacterial parasite in certain terrestrial habitats [6].

The most recent dsRNA phage isolations were reported in Europe and Asia from diverse environmental sources: Pseudomonas phage phiNN was isolated contemporarily with its host bacterial strain Pseudomonas sp. B314 from a fresh water sample in Finland [14], whereas the isolation source of Pseudomonas phage phiYY was hospital sewage in China [15]. PhiYY was isolated together with Pseudomonas aeruginosa strain PAO38, and it also infects several other clinical strains of $P$. aeruginosa [15]. P. aeruginosa is an opportunistic human pathogen, which causes serious infections in immune-compromised individuals. These recent discoveries demonstrate, that dsRNA phages have adapted to varying habitats in globally distant locations.

The dsRNA phages described above share genetic and structural characteristics (overall virion morphology, genome type and genome organization) with phage phi6, the prototype virus of the Cystoviridae. These features clearly distinguish them from other viruses and demonstrate their relatedness. Consequently, they should be included into the Cystoviridae family.

Table 1 Proposed members of the revised Cystoviridae family

\begin{tabular}{|c|c|c|c|c|c|c|}
\hline Member & Abbreviation & $\begin{array}{l}\text { GenBank accession } \\
\text { number (L, M and } S \\
\text { segments) }\end{array}$ & Isolation host & Isolation source & Country & References \\
\hline $\begin{array}{l}\text { Pseudomonas virus phi6 } \\
\text { (type species) }\end{array}$ & phi6 & $\begin{array}{l}\text { M17461, M17462, } \\
\text { M12921 }\end{array}$ & $\begin{array}{l}\text { P. syringae pv. phaseoli- } \\
\text { cola HB10Y }\end{array}$ & $\begin{array}{l}\text { Phaseolus vulgaris } \\
\text { (bean) }\end{array}$ & USA & [5] \\
\hline Pseudomonas virus phi8 & phi8 & $\begin{array}{l}\text { AF226851, AF226852, } \\
\text { AF226853 }\end{array}$ & $\begin{array}{l}\text { P. syringae pv. phaseoli- } \\
\text { cola LM } 2333\end{array}$ & Pisum sativum (pea) & USA & {$[8,9]$} \\
\hline $\begin{array}{l}\text { Pseudomonas virus } \\
\text { phi12 }\end{array}$ & phi12 & $\begin{array}{l}\text { AF408636, AY039807, } \\
\text { AY034425 }\end{array}$ & $\begin{array}{l}\text { P. syringae pv. phaseoli- } \\
\text { cola LM2333 }\end{array}$ & $\begin{array}{l}\text { Ocimum basilicum } \\
\text { (bacil) }\end{array}$ & USA & {$[8,11,12]$} \\
\hline $\begin{array}{l}\text { Pseudomonas virus } \\
\text { phi13 }\end{array}$ & phi13 & $\begin{array}{l}\text { AF261668, AF261667, } \\
\text { AF261666 }\end{array}$ & $\begin{array}{l}\text { P. syringae pv. phaseoli- } \\
\text { cola LM } 2333\end{array}$ & $\begin{array}{l}\text { Raphanus sativum } \\
\text { (radish) }\end{array}$ & USA & {$[8,10]$} \\
\hline $\begin{array}{l}\text { Pseudomonas virus } \\
\text { phi2954 }\end{array}$ & phi2954 & $\begin{array}{l}\text { FJ608823, FJ608824, } \\
\text { FJ608825 }\end{array}$ & $\begin{array}{l}\text { P. syringae pv. phaseoli- } \\
\text { cola LM } 2489\end{array}$ & Raphanus sativum & USA & [13] \\
\hline $\begin{array}{l}\text { Pseudomonas virus } \\
\text { phiNN }\end{array}$ & phiNN & $\begin{array}{l}\text { KJ957164, KJ957165, } \\
\text { KJ957166 }\end{array}$ & P. sp. B314 & Lake water & Finland & [14] \\
\hline $\begin{array}{l}\text { Pseudomonas virus } \\
\text { phiYY }\end{array}$ & phiYY & $\begin{array}{l}\text { KX074201, KX074202, } \\
\text { KX074203 }\end{array}$ & P. aeruginosa $\mathrm{PAO} 38$ & Hospital sewage & China & [15] \\
\hline
\end{tabular}




\section{Cystoviruses have one or two icosahedral protein shells surrounded by an envelope}

The virion organization of the proposed members of the Cystoviridae, if described, resembles that of the type species. The virions are enveloped and the tri-segmented genome is enclosed in one or two concentric, icosahedrally symmetric protein shells $[16,17]$. Studies on phi6 have revealed that the innermost protein shell of the virion, also referred to as the polymerase complex (PC), is composed of the major capsid protein (MCP) P1, the RdRP P2, the packaging NTPase P4 and the minor protein $\mathrm{P} 7$ [18]. The structural framework of the PC consists of 60 asymmetric dimers of the MCP $\mathrm{P} 1$ arranged into $\mathrm{T}=1$ architecture, characteristic of dsRNA viruses $[19,20]$.

The second protein layer, or the nucleocapsid (NC) shell, of the phi6 virion is constituted by 200 trimers of protein $\mathrm{P} 8$ on a $\mathrm{T}=13$ icosahedral lattice [18-20]. The near-atomic structure of the phi6 NC shell has been recently solved [21]. Interestingly, phage phi8 is lacking this NC shell, and therefore has a single protein shell surrounding the genome [16].

The outermost layer of cystoviruses is a lipid envelope, containing host-derived phospholipids [22] and phageencoded membrane proteins [23]. Host binding spikes, composed of protein $\mathrm{P} 3$, protrude from the virion surface [24]. Spike proteins differ between cystoviruses, resulting in varying host specificities [25-27].

\section{Genome organizations of cystoviruses are highly similar}

All the proposed members of the Cystoviridae family have a dsRNA genome, which is divided into three separate segments designated according to their size as L (large, $6.4-7.1 \mathrm{~kb}$ ), $\mathrm{M}$ (medium, $3.6-4.7 \mathrm{~kb}$ ) and $\mathrm{S}$ (small, 2.3 $-3.2 \mathrm{~kb})[9-15,28-30]$. The total genome size varies from $12.7 \mathrm{~kb}$ (phi2954) to $15.0 \mathrm{~kb}$ (phi8). The GC content of the cystovirus genomes ranges from $53.4 \%$ (phi2954) to $58.8 \%$ (phiYY). Cystoviruses share limited similarity at the nucleotide sequence level (Table 2), with the exception of phi6 and phiNN, which are genetically considerably similar $(79.5 \%$, $51.2 \%$ and $83.4 \%$ nucleotide sequence similarities for $\mathrm{L}, \mathrm{M}$ and $\mathrm{S}$ segments, respectively). The high genetic similarity between phi6 and phiNN is surprising, considering the fact, that these two viruses were isolated from different habitats (plant debris and fresh water sample) at globally distant locations (Nebraska, USA and Jyväskylä, Finland) at an interval of over 40 years $[5,14]$.

Genome organization of cystoviruses is highly similar and they encode a comparable set of proteins [9-15, 28-30]. Genes are grouped into functional groups in each genome segment: The L-segment encodes proteins forming the virion core (P1, P2, P4 and P7), the $\mathrm{M}$-segment contains genes for the host recognition complex (P3 and P6), and the $\mathrm{S}$-segment encodes the $\mathrm{NC}$ shell protein (P8; as an exception, phi8 $\mathrm{P} 8$ is a membrane protein), the major membrane protein (P9), putative membrane morphogenetic factor $\mathrm{P} 12$ as well as the protein needed in host cell lysis (P5). In each segment, the coding region is flanked by non-coding regions, which are essential in genome packaging and replication. Comparative genome analysis reveals an intergenome rearrangement in Pseudomonas phage phi8: gene 7 is located at the $3^{\prime}$ terminus of the L-segment in phage phi8, but at the $5^{\prime}$ terminus of the L-segment in all other proposed cystoviruses (Fig. 1). Otherwise the order of the genes in the genome segments seems to be the same in all proposed members of the Cystoviridae.

A moderate level of amino acid sequence similarity is seen among the proposed cystoviruses between the major structural proteins and essential enzymes, which are encoded by the L- and S-segments (Fig. 1). For instance, when comparing phages phi6 and phiNN, the protein products of the S- and L-segment are almost identical (89-99\% amino acid sequence similarity; Fig. 1a,c), whereas more diversity is seen between the corresponding proteins of the M-segments (41 - 70\% amino acid sequence similarity; Fig. 1b; [14]). This higher genetic flexibility in the M-segment, encoding the host recognition complex, may reflect the evolutionary pressure to broaden the host range and adapt to new habitats [14]. Interestingly though, $36-85 \%$ amino acid sequence similarity can be detected between the corresponding putative host recognition proteins of phages phiYY, phi12 and phi13, despite their taxonomically distant host bacteria (phiYY infects human pathogen $P$. aeruginosa, whereas phi12 and phi13 infect plant pathogen $P$. syringae).

We conducted phylogenetic analyses separately for each of the cystoviral genome segments based on the nucleotide sequences (Fig. 2). All the deduced phylogenetic trees show close relatedness between phages phi6 and phiNN. Otherwise, the clustering was different in each of the three trees, suggesting reassortment of genome segments between the proposed species during their evolution. The exchange of genome segments between some of the cystoviral isolates has also been experimentally demonstrated $[8,10,13]$ and can be detected in natural dsRNA phage isolates $[6,7]$.

\section{Cystoviruses have lytic life cycles}

All the proposed members of the Cystoviridae are virulent viruses, which induce lysis of their bacterial host cells at the end of viral reproduction cycle. However, it has been shown, that phage phi6, the type member of the Cystoviridae, may also establish a carrier state in the host bacterium [31-33]. 
Table 2 Nucleotide sequence similarities (\%) between the cystoviral genome segments. Color code: $>95 \%=$ dark grey, $>75 \%=$ medium grey, $>50 \%=$ light grey

\begin{tabular}{|c|c|c|c|c|c|c|c|}
\hline \multicolumn{8}{|c|}{ Nucleotide sequence similarities $(\%)$ between the L-segments ${ }^{a}$} \\
\hline Phage & phi6 & phi8 & phi12 & phi13 & phi2954 & phiNN & phiYY \\
\hline phi6 & 100 & 38.47 & 36.42 & 48.84 & 36.01 & 79.46 & 48.46 \\
\hline phi8 & & 100 & 35.8 & 38.96 & 34.82 & 38.51 & 38 \\
\hline phi12 & & & 100 & 35.98 & 51.13 & 36.07 & 35.48 \\
\hline phi13 & & & & 100 & 34.9 & 48.62 & 62.93 \\
\hline phi2954 & & & & & 100 & 35.74 & 34.76 \\
\hline phiNN & & & & & & 100 & 47.84 \\
\hline phiYY & & & & & & & 100 \\
\hline \multicolumn{8}{|c|}{ Nucleotide sequence similarities $(\%)$ between the M-segments ${ }^{\mathrm{a}}$} \\
\hline & phi6 & phi8 & phi12 & phi13 & phi2954 & phiNN & phiYY \\
\hline phi6 & 100 & 38.17 & 38.99 & 40.34 & 39.2 & 51.18 & 35.34 \\
\hline phi8 & & 100 & 38.47 & 39.75 & 38.75 & 36.48 & 35.91 \\
\hline phi12 & & & 100 & 61.26 & 37.46 & 39.15 & 38.32 \\
\hline phi13 & & & & 100 & 37.5 & 40.66 & 39.43 \\
\hline phi2954 & & & & & 100 & 37.32 & 34.89 \\
\hline phiNN & & & & & & 100 & 37.25 \\
\hline phiYY & & & & & & & 100 \\
\hline \multicolumn{8}{|c|}{ Nucleotide sequence similarities $(\%)$ between the S-segments ${ }^{\mathrm{a}}$} \\
\hline & phi6 & phi8 & phi12 & phi13 & phi2954 & phiNN & phiYY \\
\hline phi6 & 100 & 38.41 & 34.74 & 40.48 & 37.39 & 83.42 & 40.79 \\
\hline phi8 & & 100 & 33.3 & 37.13 & 34.02 & 37.7 & 37.11 \\
\hline phi12 & & & 100 & 33.22 & 46.43 & 33.48 & 38.57 \\
\hline phi13 & & & & 100 & 34.45 & 40.23 & 37.1 \\
\hline phi2954 & & & & & 100 & 36.41 & 41.64 \\
\hline phiNN & & & & & & 100 & 40.18 \\
\hline phiYY & & & & & & & 100 \\
\hline
\end{tabular}

${ }^{a}$ Determined using Clustal Omega Multiple Alignment [50]

Different stages of the infection cycle have been described comprehensively for phi6. Upon infection, the phi6 virion adsorbs to type IV pilus on bacterial cell surface [34, 35]. As the pilus retracts, the virion is brought into contact with the bacterial outer membrane. Phages phiNN and phi2954 also use this type IV pilus-mediated infection strategy [13, 14], whereas phages phi8, phi12 and phi13 bind the host cell directly through rough LPS on the cell surface [8]. In each case, $\mathrm{P} 3$ protein complex is required for the initial binding to the host bacterium $[9,10,12-14,29,34]$. It has been suggested, that the $\mathrm{P} 3$ protein complex consists of a single polypeptide or its multimer in phages phi6, phi2954 and phiNN $[13,14,29]$, whereas in phages phi8, phi12, phi13 and phiYY the $\mathrm{P} 3$ complex is heteromeric, containing two or 

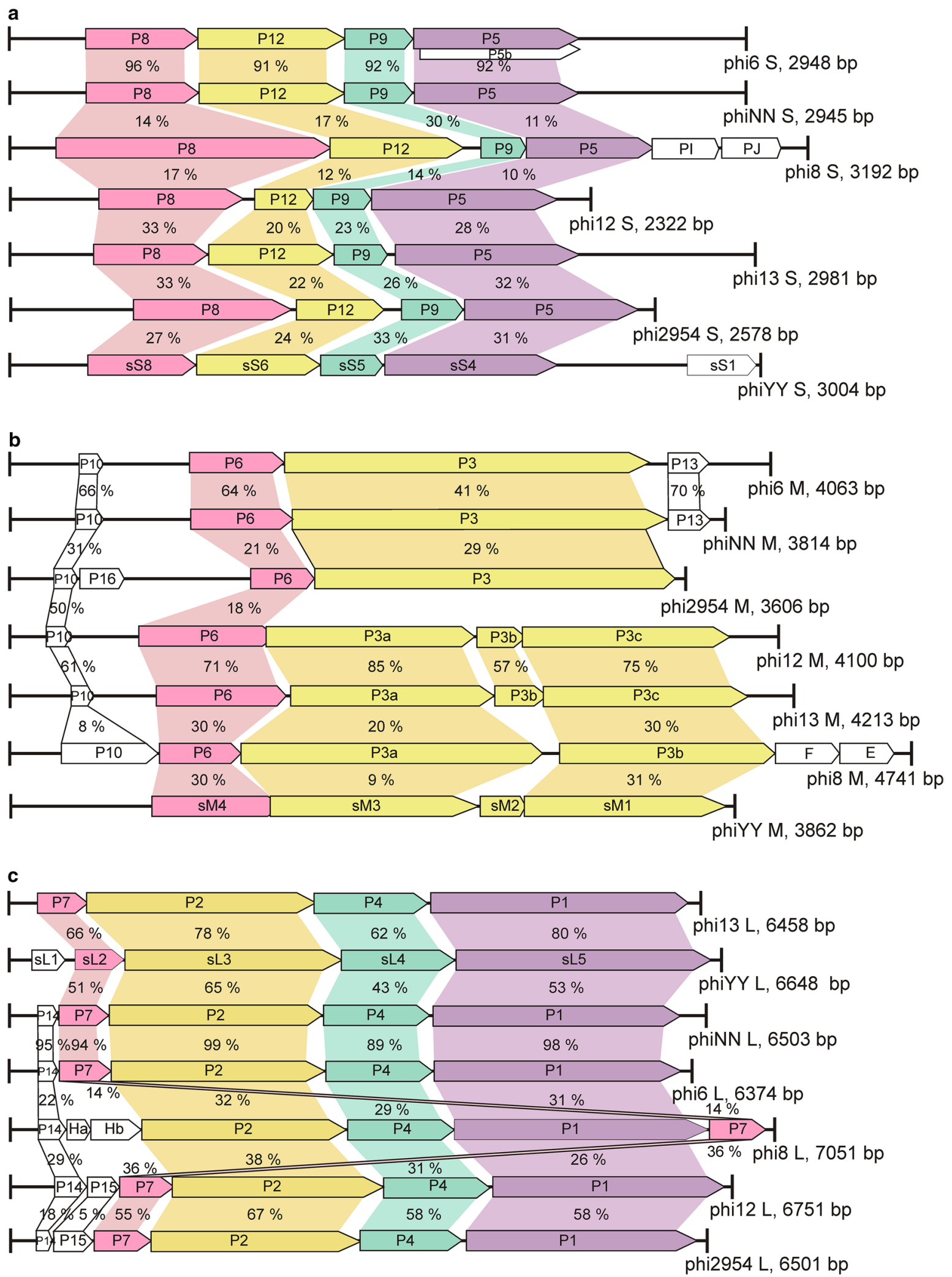

Fig. 1 Genome maps of the segments $S$ (a), M (b) and L (c) of the proposed members of the Cystoviridae. Open reading frames (ORFs) of the predicted positive strands are depicted and amino acid sequence similarities (\%) between corresponding ORFs are indi- cated. Comparisons were conducted with EMBOSS Needle Pairwise Sequence Alignment [51]. The order of the genome segments follows the clustering in the phylogenetic trees presented in Fig. 2 
a

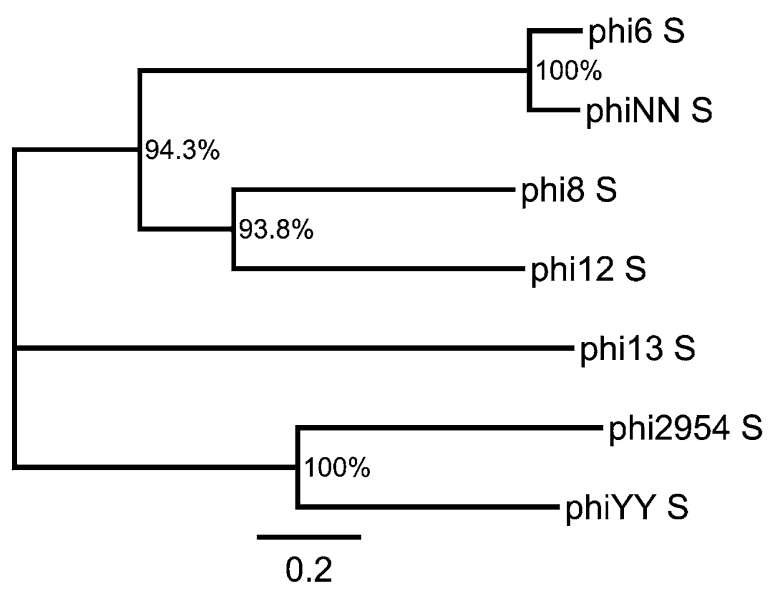

b

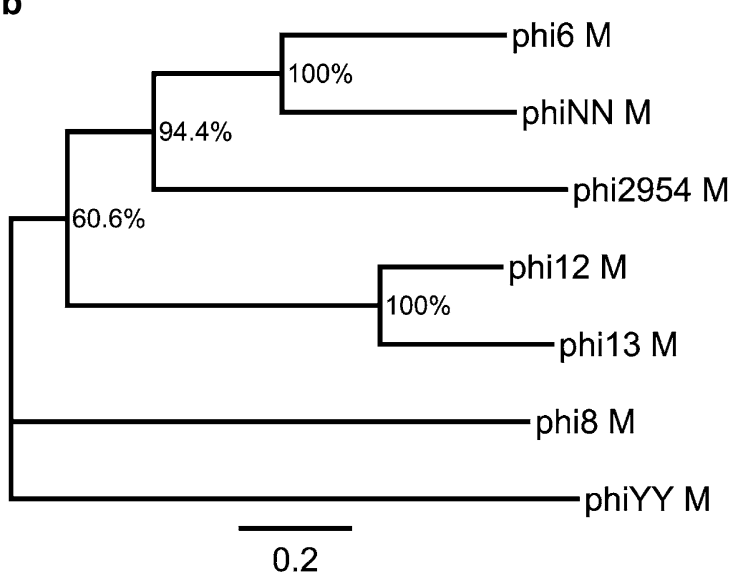

C

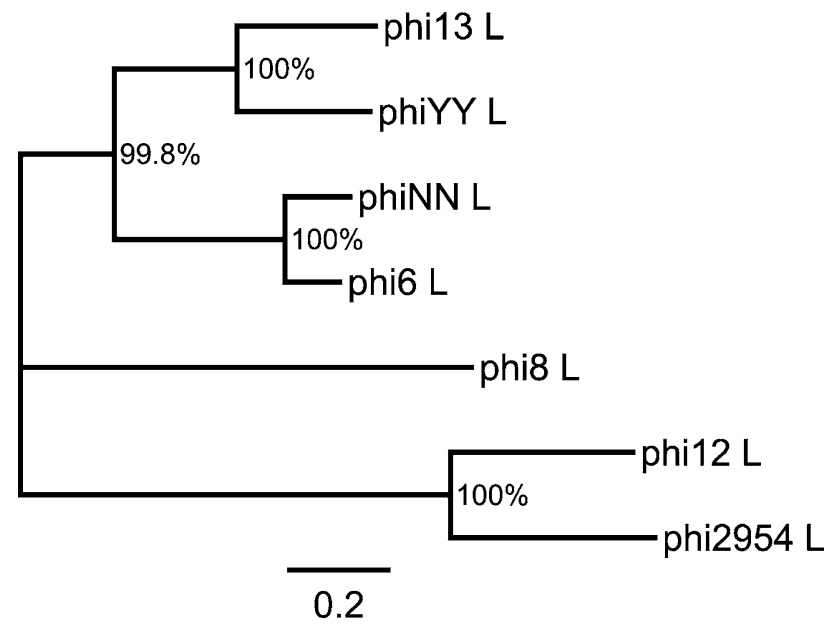

Fig. 2 Phylogenetic trees showing relationships between proposed members of the Cystoviridae based on nucleotide sequence comparisons of the segments S (a), M (b) and L (c). The trees were constructed with maximum likelihood method using Mega 7.0 [52]. The robustness was statistically evaluated by bootstrap analysis with 1000 replicates. Bootstrap values greater than $50 \%$ are indicated at the branch points. Finally, the trees were visualized using FigTree v1.3.1 three different polypeptides (P3a, P3b, P3c) $[9,10,12,15]$. The $\mathrm{P} 3$ protein of phi6 is anchored to the viral membrane via phage membrane protein P6. P6 protein mediates the fusion between the viral envelope and bacterial outer membrane, ultimately releasing the $\mathrm{NC}$ into the periplasmic space [36].

The removal of the viral membrane from the $\mathrm{NC}$ releases the lytic enzyme P5, which then digests the host peptidoglycan layer [37, 38]. The rupturing of the peptidoglycan layer enables the NC to reach the cytoplasmic membrane. The NC penetrates the cytoplasmic membrane using endocytic-like mechanism [39]. The NC outer shell (formed by P8) dissociates in the cytoplasm, revealing the PC $[40,41]$. This activates the virion-associated RdRP, which then launches viral transcription within the PC [42]. Semi-conservative transcription produces full-length, polycistronic mRNA molecules of the genome segments [43]. At the first phase of the infection, approximately equal amounts of transcripts are produced from each genome segment $[44,45]$. However, only the transcripts of the L-segment are efficiently produced, which leads to the accumulation of PC proteins and, consequently, to the formation of empty PCs. The packaging NTPase P4 translocates one copy of each type of genome segment transcripts inside the newly synthesized empty PCs [46, 47]. The transcripts are packaged, based on the 5 ' terminal packaging signals, in the order $\mathrm{S}, \mathrm{M}$ and $\mathrm{L}$. The packaging triggers the negative-strand synthesis within the PC, ultimately resulting in mature, double-stranded forms of all three genome segments [42]. After the replication, the plus-strand synthesis is again switched on. During this late phase of infection, transcription of the S- and M-segments predominates $[44,45]$. This leads to the production of proteins needed in virion assembly. The NC shell assembles around the PC [40, 48], after which viral membrane, derived from the host cytoplasmic membrane, encloses the NC [49]. Finally P3 spikes are attached onto the virion surface resulting in mature virion structure. Lytic enzyme P5 and membrane protein P10 mediate the lysis of the host cell, ultimately releasing the newly synthesized virions into the environment [37, 38].

\section{Taxonomic structure of the cystoviruses}

Despite the fact, that the identified dsRNA phages commonly share a relatively low degree of nucleotide sequence identity ( $<50 \%$, except for phi6 and phiNN; Table 2$)$, their overall virion structures (one or two icosahedral capsids, enclosed by a lipid envelope) and genome characteristics (genome type and size, GC content, genome organization and gene synteny) are strikingly similar. They undoubtedly belong to the Cystoviridae family. We have proposed 95\% nucleotide sequence identity as the criterion for demarcation of species in the Cystoviridae family. This initial criterion 
may be adjusted when new cystovirus isolates are described. Based on the current criteria the members of each of the proposed species should differ from those of other species by more than $5 \%$ at the nucleotide sequence level. Consequently, Pseudomonas phages phi8, phi12, phi13, phi2954, phiNN and phiYY should be included into the Cystoviridae family as distinct species (Table 1).

The phylogenetic analyses indicate close relationship between the type member of the genus Cystovirus (Pseudomonas virus phi6) and one of the proposed new species, Pseudomonas virus phiNN, whereas the other proposed species are more distantly related (Fig. 2). Furthermore, the three genome segments of these isolates apparently have distinct evolutionary histories (due to frequent genome segment reassortments). These viruses clearly belong to the Cystoviridae family, but due to the low number of isolates it is difficult to clarify the taxonomic structure within the family. Therefore we propose that all the new species belong to the same genus, Cystovirus.

Acknowledgements The authors acknowledge Professor Dennis Bamford who has contributed to the description of the Cystoviridae family in the previous ICTV Reports.

\section{Compliance with ethical standards}

Disclaimer The taxonomic changes suggested here have not been endorsed by the ICTV Executive Committee, may differ from any new taxonomy that is ultimately approved by the ICTV, and are presented for discussion only but have no official standing. This article is related to an ongoing taxonomic proposal (2017.016B.U.v1.Cystovirus_6sp. zip), submitted to the ICTV but not yet accepted at the time of submission. M.M.P is the Chair of the Cystoviridae Study Group of the ICTV Bacterial and Archaeal Viruses Subcommittee.

Funding This study was funded by the Finnish Centre of Excellence Program of the Academy of Finland; the CoE in Biological Interactions 2012-2017 (\#252411), Academy of Finland grants \#272507 (M.M.P.) and \#266879 (L-R.S.), Sigrid Juselius Foundation (M.M.P.) and by Jane and Aatos Erkko Foundation (L-R.S.).

Conflict of interest The authors declare that they have no conflict of interest.

Ethical approval The article does not contain any studies with human participants or animals performed by any of the authors.

Data availability The DNA sequence datasets analysed during the current study are available in the GenBank repository (https://www.ncbi. nlm.nih.gov/genbank/). GenBank accession numbers for the sequences can be found in Table 1.

\section{References}

1. Mertens P (2004) The dsRNA viruses. Virus Res 101:3-13

2. Poranen MM, Bamford DH (2012) Assembly of large icosahedral double-stranded RNA viruses. Adv Exp Med Biol 726:379-402
3. Luque D, González JM, Garriga D, Ghabrial SA, Havens WM, Trus B, Verdaguer N, Carrascosa JL, Castón JR (2010) The T=1 capsid protein of Penicillium chrysogenum virus is formed by a repeated helix-rich core indicative of gene duplication. J Virol 84:7256-7266

4. El Omari K, Sutton G, Ravantti JJ, Zhang H, Walter TS, Grimes JM, Bamford DH, Stuart DI, Mancini EJ (2013) Plate tectonics of virus shell assembly and reorganization in phage phi8, a distant relative of mammalian reoviruses. Structure 21:1384-1395

5. Vidaver AK, Koski RK, Van Etten JL (1973) Bacteriophage phi6: a lipid-containing virus of Pseudomonas phaseolicola. J Virol 11:799-805

6. Silander OK, Weinreich DM, Wright KM, O'Keefe KJ, Rang CU, Turner PE, Chao L (2005) Widespread genetic exchange among terrestrial bacteriophages. Proc Natl Acad Sci USA 102:19009-19014

7. O'Keefe KJ, Silander OK, McCreery H, Weinreich DM, Wright KM, Chao L, Edwards SV, Remold SK, Turner PE (2010) Geographic differences in sexual reassortment in RNA phage. Evolution 64:3010-3023

8. Mindich L, Qiao X, Qiao J, Onodera S, Romantschuk M, Hoogstraten D (1999) Isolation of additional bacteriophages with genomes of segmented double-stranded RNA. J Bacteriol 181:4505-4508

9. Hoogstraten D, Qiao X, Sun Y, Hu A, Onodera S, Mindich L (2000) Characterization of phi8, a bacteriophage containing three double-stranded RNA genomic segments and distantly related to phi6. Virology 272:218-224

10. Qiao X, Qiao J, Onodera S, Mindich L (2000) Characterization of phi13, a bacteriophage related to phi6 and containing three dsRNA genomic segments. Virology 275:218-224

11. Gottlieb P, Potgieter C, Wei H, Toporovsky I (2002) Characterization of phi12, a bacteriophage related to phi6: nucleotide sequence of the large double-stranded RNA. Virology 295:266-271

12. Gottlieb P, Wei H, Potgieter C, Toporovsky I (2002) Characterization of phi12, a bacteriophage related to phi6: nucleotide sequence of the small and middle double-stranded RNA. Virology 293:118-124

13. Qiao X, Sun Y, Qiao J, Di Sanzo F, Mindich L (2010) Characterization of phi2954, a newly isolated bacteriophage containing three dsRNA genomic segments. BMC Microbiol 10:55. https:// doi.org/10.1186/1471-2180-10-55

14. Mäntynen S, Laanto E, Kohvakka A, Poranen MM, Bamford JK, Ravantti JJ (2015) New enveloped dsRNA phage from freshwater habitat. J Gen Virol 96:1180-1189

15. Yang Y, Lu S, Shen W, Zhao X, Shen M, Tan Y, Li G, Li M, Wang J, Hu F, Le S (2016) Characterization of the first double-stranded RNA bacteriophage infecting Pseudomonas aeruginosa. Sci Rep 6:38795

16. Jäälinoja HT, Huiskonen JT, Butcher SJ (2007) Electron cryomicroscopy comparison of the architectures of the enveloped bacteriophages phi6 and phi8. Structure 15:157-167

17. Wei H, Cheng RH, Berriman J, Rice WJ, Stokes DL, Katz A, Morgan DG, Gottlieb P (2009) Three-dimensional structure of the enveloped bacteriophage phi12: an incomplete $\mathrm{T}=13$ lattice is superposed on an enclosed $\mathrm{T}=1$ shell. PLoS One 4:e6850

18. Bamford DH, Mindich L (1980) Electron microscopy of cells infected with nonsense mutants of bacteriophage phi6. Virology 107:222-228

19. Butcher SJ, Dokland T, Ojala PM, Bamford DH, Fuller SD (1997) Intermediates in the assembly pathway of the double-stranded RNA virus phi6. EMBO J 16:4477-4487

20. Huiskonen JT, de Haas F, Bubeck D, Bamford DH, Fuller SD, Butcher SJ (2006) Structure of the bacteriophage phi6 nucleocapsid suggests a mechanism for sequential RNA packaging. Structure 14:1039-1048 
21. Sun Z, El Omari K, Sun X, Ilca SL, Kotecha A, Stuart DI, Poranen MM, Huiskonen JT (2017) Double-stranded RNA virus outer shell assembly by bona fide domain-swapping. Nat Commun 8:14814

22. Laurinavičius S, Bamford DH, Somerharju P (2007) Transbilayer distribution of phospholipids in bacteriophage membranes. Biochim Biophys Acta 1768:2568-2577

23. Sinclair JF, Tzagoloff A, Levine D, Mindich L (1975) Proteins of bacteriophage phi6. J Virol 16:685-695

24. Stitt BL, Mindich L (1983) The structure of bacteriophage phi6: protease digestion of phi6 virions. Virology 127:459-462

25. Duffy S, Turner PE, Burch CL (2006) Pleiotropic costs of niche expansion in the RNA bacteriophage phi6. Genetics 172:751-757

26. Ferris MT, Joyce P, Burch CL (2007) High frequency of mutations that expand the host range of an RNA virus. Genetics 176:1013-1022

27. Ford BE, Sun B, Carpino J, Chapler ES, Ching J, Choi Y, Jhun K, Kim JD, Lallos GG, Morgenstern R, Singh S, Theja S, Dennehy JJ (2014) Frequency and fitness consequences of bacteriophage phi6 host range mutations. PLoS One 9:e113078

28. McGraw T, Mindich L, Frangione B (1986) Nucleotide sequence of the small double-stranded RNA segment of bacteriophage phi6: novel mechanism of natural translational control. J Virol 58:142-151

29. Gottlieb P, Metzger S, Romantschuk M, Carton J, Strassman J, Bamford DH, Kalkkinen N, Mindich L (1988) Nucleotide sequence of the middle dsRNA segment of bacteriophage phi6: placement of the genes of membrane-associated proteins. Virology 163:183-190

30. Mindich L, Nemhauser I, Gottlieb P, Romantschuk M, Carton J, Frucht S, Strassman J, Bamford DH, Kalkkinen N (1988) Nucleotide sequence of the large double-stranded RNA segment of bacteriophage phi6: genes specifying the viral replicase and transcriptase. J Virol 62:1180-1185

31. Romantschuk M, Bamford DH (1981) phi6-Resistant phageproducing mutants of Pseudomonas phaseolicola. J Gen Virol $56: 287-295$

32. Sun Y, Qiao X, Mindich L (2004) Construction of carrier state viruses with partial genomes of the segmented dsRNA bacteriophages. Virology 319:274-279

33. Onodera S, Olkkonen VM, Gottlieb P, Strassman J, Qiao XY, Bamford DH, Mindich L (1992) Construction of a transducing virus from double-stranded RNA bacteriophage phi6: establishment of carrier states in host cells. J Virol 66:190-196

34. Bamford DH, Palva ET, Lounatmaa K (1976) Ultrastructure and life cycle of the lipid-containing bacteriophage phi6. J Gen Virol 32:249-259

35. Roine E, Raineri DM, Romantschuk M, Wilson M, Nunn DN (1998) Characterization of type IV pilus genes in Pseudomonas syringae pv. tomato DC3000. Mol Plant Microbe Interact 11:1048-1056

36. Bamford DH, Romantschuk M, Somerharju PJ (1987) Membrane fusion in prokaryotes: bacteriophage phi6 membrane fuses with the Pseudomonas syringae outer membrane. EMBO J 6:1467-1473
37. Mindich L, Lehman J (1979) Cell wall lysin as a component of the bacteriophage phi6 virion. J Virol 30:489-496

38. Caldentey J, Bamford DH (1992) The lytic enzyme of the Pseudomonas phage phi6. Purification and biochemical characterization. Biochim Biophys Acta 1159:44-50

39. Poranen MM, Daugelavicius R, Ojala PM, Hess MW, Bamford DH (1999) A novel virus-host cell membrane interaction. Membrane voltage-dependent endocytic-like entry of bacteriophage straight phi6 nucleocapsid. J Cell Biol 147:671-682

40. Olkkonen VM, Ojala PM, Bamford DH (1991) Generation of infectious nucleocapsids by in vitro assembly of the shell protein on to the polymerase complex of the dsRNA bacteriophage phi6. J Mol Biol 218:569-581

41. Cvirkaitė-Krupovič V, Poranen MM, Bamford DH (2010) Phospholipids act as secondary receptor during the entry of the enveloped, double-stranded RNA bacteriophage phi6. J Gen Virol 91:2116-2120

42. Poranen MM, Tuma R, Bamford DH (2005) Assembly of doublestranded RNA bacteriophages. Adv Virus Res 64:15-43

43. Usala SJ, Brownstein BH, Haselkorn R (1980) Displacement of parental RNA strands during in vitro transcription by bacteriophage phi6 nucleocapsids. Cell 19:855-862

44. Coplin DL, Van Etten JL, Koski RK, Vidaver AK (1975) Intermediates in the biosynthesis of double-stranded ribonucleic acids of bacteriophage phi6. Proc Natl Acad Sci USA 72:849-853

45. Emori Y, Iba H, Okada Y (1983) Transcriptional regulation of three double-stranded RNA segments of bacteriophage phi6 in vitro. J Virol 46:196-203

46. Qiao X, Casini G, Qiao J, Mindich L (1995) In vitro packaging of individual genomic segments of bacteriophage phi6 RNA: serial dependence relationships. J Virol 69:2926-2931

47. Frilander M, Bamford DH (1995) In vitro packaging of the single-stranded RNA genomic precursors of the segmented doublestranded RNA bacteriophage phi6: the three segments modulate each other's packaging efficiency. J Mol Biol 246:418-428

48. Poranen MM, Paatero AO, Tuma R, Bamford DH (2001) Selfassembly of a viral molecular machine from purified protein and RNA constituents. Mol Cell 7:845-854

49. Johnson MD, Mindich L (1994) Plasmid-directed assembly of the lipid-containing membrane of bacteriophage phi6. J Bacteriol 176:4124-4132

50. Sievers F, Wilm A, Dineen D, Gibson TJ, Karplus K, Li W, Lopez R, McWilliam H, Remmert M, Soding J, Thompson JD, Higgins DG (2011) Fast, scalable generation of high-quality protein multiple sequence alignments using Clustal Omega. Mol Syst Biol 7:539

51. Rice P, Longden I, Bleasby A (2000) EMBOSS: the European molecular biology open software suite. Trends Genet 16:276-277

52. Kumar S, Stecher G, Tamura K (2016) MEGA7: molecular evolutionary genetics analysis version 7.0 for bigger datasets. Mol Biol Evol 33:1870-1874 